\title{
Enhanced fibrinolytic protease production by Serratia marcescens RSPB11 through Plackett-Burman and response surface methodological approaches
}

\author{
Paruchuru Lakshmi Bhargavi, Reddy Shetty Prakasham* \\ Bioengineering and Environmental Sciences CSIR-Indian Institute of Chemical Technology Hyderabad - 500 607, India.
}

\section{ARTICLE INFO \\ Article history: \\ Received on: 10/11/2015 \\ Revised on: 03/01/2016 \\ Accepted on: 27/02/2016 \\ Available online: 21/06/2016}

Key words:

Fibrinolytic enzyme;

Serralysin; Serratia

marcescens; Plackett-

Burman design; Response

surface methodology.

\begin{abstract}
A well characterized alkaline metalloprotease enzyme called serralysin with fibrinolytic activity has been reported in the newly isolated Serratia marcescens RSPB11. In view of its potential application in thrombolytic therapy this study has been made for understanding the nutritional parameters requirement needed for production. Therefore, medium components required for the production of serralysin were optimized using a two step statistical approach. Fermentation variables were selected in accordance with the Plackett-Burman design and were further optimized via response surface methodological approach. A total of seven parameters viz., casein, dextrose, $\mathrm{KH}_{2} \mathrm{PO}_{4}, \mathrm{MgSO}_{4}, \mathrm{NaCl}, \mathrm{CaCl}_{2}$ and inoculum have been considered for the optimization studies. The statistical model was constructed via central composite design (CCD) using five screened variables (casein, dextrose, $\mathrm{KH}_{2} \mathrm{PO}_{4}, \mathrm{CaCl}_{2}$ and inoculum size). An overall $51.8 \%$ increase in protease production was achieved in the optimized medium as compared with the unoptimized casein medium. With the application of statistical design methodology serralysin production increased significantly with optimized casein medium $(23910 \mathrm{U} / \mathrm{ml})$ when compared to yeast extract-peptone medium $(5363 \mathrm{U} / \mathrm{ml})$.
\end{abstract}

\section{INTRODUCTION}

Serralysin is a proteolytic enzyme initially isolated from Serratia marcescens, a potentially pathogenic bacterium, found in the gut of the Japanese silkworm. The isolated protein belongs to alkaline metalloprotease and known to activate the Hageman factor-kallikrein-kinin systems of mammals and directly involve in degradation or inhibition of $\mathrm{IgG}$ and $\operatorname{IgA}$ immune factors as well as regulatory proteins such as 2-macroglobulin, 2-anplasmin and anti-thrombin III [1]. Because of these functionalities, it is administered in dietary supplements for the treatment of assorted inflammatory disorders in Asia and Europe, it gained wide clinical usage as cardiovascular, anti-inflammatory, respiratory, or immune support agent and as an adjunct to antibiotic therapy and to treat other chronic inflammatory diseases, like atherosclerosis, arthritis, bronchitis, carpel tunnel syndrome, fibrocystic breast disease, and sinusitis [2].

\section{* Corresponding Author}

Prakasham Reddy Shetty, Bioengineering and Environmental Sciences CSIR-Indian Institute of Chemical Technology Hyderabad - 500 607,

India.Email:prakasam@iict.res.in
Interestingly, this enzyme production is mostly reported from clinical isolates $[3,4]$ however, reports from marine microbial strain, Pseudomonas sp., also noticed in the literature [5, 6]. Much attention has been focused on serralysin production by Serratia marcescens due to its potential for higher enzyme yields compared to literature reports [7, 8]. Fibrin and fibrinogen degradation activity of serralysin which acts like plasmin in human body (directly degrades the fibrin unlike plasminogen activator) produced by Serratia marcescens RSPB11 has been reported earlier [9]. Chromatographically purified enzyme has been characterized in terms of $\mathrm{pH}$ and temperature, where the serralysin produced by this strain was alkaline thermostable metalloprotease with effective application as thrombolytic therapeutic agent. The conventional method of optimization involves variation of one parameter at a time and keeping the others constant. This is a extremely time consuming and expensive method when a large number of variables are considered and also does not often bring up the effect of interaction of various parameters as compared to factorial design [10]. Besides this, it is a tedious, cumbersome, and time-consuming process especially when a large number of parameters are taken into account. An alternative and more efficient approach is the use of statistical method [11]. 
The Plackett-Burman factorial designs facilitates the screening of main factors from a large number of process variables, and these designs are thus quite useful in preliminary studies in which the principal objective is to select variables that can be fixed or eliminated in further optimization processes. In addition, response surface methodology (RSM) is an efficient strategic experimental tool by which the optimal conditions of a multivariable system may be determined [12]. A combination of Plackett-Burman and RSM was applied successfully for optimizing process parameters for the production of different biomolecules from different microbes like protease, asparginase from Bacillus sp., Serratia rubidea [13-15], laccase from Coriolus versicolor [16], fibrinolytic protease from gram negative Bacillus sp., [17], lipase from Rhodotorula sp., MTCC 8737 [18], tannase from Aspergillus niger [19], polysaccharide from Neisseria meningitides [20], epothilone-B from Sorangium cellulosum [21]. A hybrid system of feed-forward neural network (FFNN) and genetic algorithm (GA) was used to optimize the fermentation conditions to enhance the alkaline protease production by Bacillus circulans [22].

Research activities related to serralysin production optimization techniques were not much available where as the mathematical modeling via evolutionary operation (EVOP) based statistical optimization technique was applied to optimize the media composition in shake-flask culture of Serratia marcescens NRRL B-23112 [23]. Therefore the present work has been carried out for optimizing the serralysin production from the newly isolated Serratia marcescens RSPB11, using a combination of Placket-Burman and response surface methodology.

\section{MATERIALS \& METHODS}

\subsection{Organism \& Inoculum preparation}

Previously isolated Serratia marcescens RSPB11 [24] was used in this study. This isolated strain was grown on nutrient agar slants at $30^{\circ} \mathrm{C}$ and sub-cultured regularly in the same media. For all experiments, inoculum developed by growing the isolate in nutrient broth at $30^{\circ} \mathrm{C}$ for $18 \mathrm{~h}$ was used after adjusting the optical density to $0.8\left(\mathrm{OD}_{600 \mathrm{~nm}}\right)$.

\subsection{Serralysin production \& enzyme assay}

Batch mode shake flask experiments were conducted at $30^{\circ} \mathrm{C}$ and $150 \mathrm{rpm}$ for $48 \mathrm{~h}$ in $250 \mathrm{ml}$ Erlenmeyer flasks containing $50 \mathrm{ml}$ of the medium. The unoptimized production medium consisting of $(\% \mathrm{w} / \mathrm{v})$ casein - 2.0, dextrose - 1.0, $\mathrm{MgSO}_{4}-0.02$, $\mathrm{KH}_{2} \mathrm{PO}_{4}-0.02, \mathrm{NaCl}-0.02, \mathrm{CaCl}_{2}-0.002$ was prepared and kept as control. While performing optimization studies differing quantities of medium components were made according to the design and all the flasks were inoculated and incubated in a shaking incubator. After the cultivation specified for each set of experiments, the culture broth was centrifuged at $10,000 \mathrm{~g}$ for 10 min in a bench-top centrifuge, and the total protease activity in the cell-free supernatant was determined. Protease activity was analyzed according to modified [24] method of Anson [25]. A

suitable blank was run simultaneously, in which TCA was added to the enzyme solution, followed by substrate addition. One unit (U) of proteolytic enzyme activity was defined as the amount of enzyme that liberated $1 \mu \mathrm{g}$ tyrosine per $\mathrm{ml}$ per minute from casein under specified assay conditions.

\subsection{Selection of significant variables by Plackett-Burman design}

For the selection of significant variables for serralysin production, a carbon source (dextrose), nitrogen source (casein), inorganic salts (potassium phosphate, magnesium sulfate, sodium chloride, calcium chloride), and size of inoculum were tested and identified via the Plackett-Burman design experiment. A total of seven parameters were included for selection, with each variable represented at two levels (lower and higher). The experimental design with the name, symbol code, and actual level of the variables is shown in Tables 1 and 2 . The principal effects of each variable on protease activity were estimated as the difference between both averages of measurements made at the higher level and at the lower level. The significance of each variable was determined via Student's t-test.

Table 1: Experimental variables at different levels used for the production of serralysin using Plackett-Burman design.

\begin{tabular}{lcccc}
\hline \multirow{2}{*}{ Variables } & \multirow{2}{*}{ Units } & Symbol & \multicolumn{2}{c}{ Experimental values } \\
\cline { 4 - 5 } & & Code & Lower & Higher \\
\hline Dextrose & $\%(w / v)$ & $\mathrm{X}_{1}$ & 0.2 & 2 \\
Casein & $\%(w / v)$ & $\mathrm{X}_{2}$ & 1 & 5 \\
$\mathrm{MgSO}_{4}$ & $\%(w / v)$ & $\mathrm{X}_{3}$ & 0.02 & 0.1 \\
$\mathrm{KH}_{2} \mathrm{PO}_{4}$ & $\%(\mathrm{w} / \mathrm{v})$ & $\mathrm{X}_{4}$ & 0.02 & 0.08 \\
$\mathrm{NaCl}$ & $\%(\mathrm{w} / \mathrm{v})$ & $\mathrm{X}_{5}$ & 0.1 & 0.4 \\
$\mathrm{CaCl}_{2}$ & $\%(\mathrm{w} / \mathrm{v})$ & $\mathrm{X}_{6}$ & 0.001 & 0.003 \\
Inoculum & $\%(\mathrm{v} / \mathrm{v})$ & $\mathrm{X}_{7}$ & 0.5 & 1.5 \\
\hline
\end{tabular}

Table 2: Chart displaying Plackett-Burman design and serralysin production to the corresponding run.

\begin{tabular}{cccccccccc}
\hline \multirow{2}{*}{$\begin{array}{c}\text { Run } \\
\text { order }\end{array}$} & $\mathbf{X}_{\mathbf{1}}$ & $\mathbf{X}_{\mathbf{2}}$ & $\mathbf{X}_{\mathbf{3}}$ & $\mathbf{X}_{\mathbf{4}}$ & $\mathbf{X}_{\mathbf{5}}$ & $\mathbf{X}_{\mathbf{6}}$ & $\mathbf{X}_{\mathbf{7}}$ & \multicolumn{2}{c}{$\begin{array}{c}\text { Enzyme activity } \\
\text { (U/ml) }\end{array}$} \\
\hline 1 & 1 & -1 & 1 & -1 & -1 & -1 & 1 & 2640 & 2988 \\
2 & 1 & 1 & -1 & 1 & -1 & -1 & -1 & 7700 & 6398 \\
3 & -1 & 1 & 1 & -1 & 1 & -1 & -1 & 9790 & 9020 \\
4 & 1 & -1 & 1 & 1 & -1 & 1 & -1 & 6050 & 5468 \\
5 & 1 & 1 & -1 & 1 & 1 & -1 & 1 & 7590 & 8892 \\
6 & 1 & 1 & 1 & -1 & 1 & 1 & -1 & 5885 & 6655 \\
7 & -1 & 1 & 1 & 1 & -1 & 1 & 1 & 17900 & 19248 \\
8 & -1 & -1 & 1 & 1 & 1 & -1 & 1 & 11440 & 10326 \\
9 & -1 & -1 & -1 & 1 & 1 & 1 & -1 & 8030 & 8378 \\
10 & 1 & -1 & -1 & -1 & 1 & 1 & 1 & 4070 & 3534 \\
11 & -1 & 1 & -1 & -1 & -1 & 1 & 1 & 16170 & 14822 \\
12 & -1 & -1 & -1 & -1 & -1 & -1 & -1 & 1870 & 3405 \\
\hline
\end{tabular}

Table 3: Estimated effects and coefficients for enzyme activity (U/ml).

\begin{tabular}{|c|c|c|c|c|}
\hline Term & Effect & Coefficient & $\mathbf{T}$ & $\mathbf{P}$ \\
\hline Constant & & 8261 & 13.03 & 0.000 \\
\hline Dextrose & -5211 & -2605 & -4.04 & $0.016^{\circ}$ \\
\hline Casein & 5156 & 2578 & 3.55 & $0.024^{b}$ \\
\hline $\mathrm{MgSO}_{4}$ & 1379 & 690 & 0.29 & $0.783^{\mathrm{a}}$ \\
\hline $\mathrm{KH}_{2} \mathrm{PO}_{4}$ & 3048 & 1524 & 2.72 & $0.053^{b}$ \\
\hline $\mathrm{NaCl}$ & -921 & -460 & -1.54 & $0.198^{\mathrm{a}}$ \\
\hline $\mathrm{CaCl}_{2}$ & 2846 & 1423 & 1.15 & $0.314^{b}$ \\
\hline Inoculum & 3414 & 1707 & 3.50 & $0.025^{b}$ \\
\hline
\end{tabular}


Table 4: Experimental codes, ranges and levels of the independent variables for response surface methodological experiment.

\begin{tabular}{lcccccc}
\hline \multicolumn{1}{c}{ Variables } & Units & Symbol & \multicolumn{3}{c}{ Levels } \\
\cline { 4 - 8 } & & Code & $\mathbf{- 2}$ & $\mathbf{- 1}$ & $\mathbf{0}$ & $\mathbf{1}$ \\
\hline Dextrose & $\%(\mathrm{w} / \mathrm{v})$ & $\mathrm{X}_{1}$ & 0.05 & 0.2 & 0.35 & 0.5 \\
Casein & $\%(\mathrm{w} / \mathrm{v})$ & $\mathrm{X}_{2}$ & 1 & 2 & 3 & 0.65 \\
$\mathrm{KH}_{2} \mathrm{PO}_{4}$ & $\%(\mathrm{w} / \mathrm{v})$ & $\mathrm{X}_{4}$ & 0.04 & 0.06 & 0.08 & 0.1 \\
$\mathrm{CaCl}_{2}$ & $\%(\mathrm{w} / \mathrm{v})$ & $\mathrm{X}_{6}$ & 0.002 & 0.004 & 0.006 & 0.008 \\
Inoculum & $\%(\mathrm{v} / \mathrm{v})$ & $\mathrm{X}_{7}$ & 0.5 & 1 & 0.12 & 0.01 \\
\hline
\end{tabular}

Table 5: CCD matrix with experimental values of protease production from Serratia marcescens RSPB11.

\begin{tabular}{|c|c|c|c|c|c|c|c|}
\hline \multirow{3}{*}{$\begin{array}{c}\text { Std order } \\
1\end{array}$} & \multirow{3}{*}{$\begin{array}{c}\text { Dextrose (\%) } \\
0.2\end{array}$} & \multirow{3}{*}{$\begin{array}{c}\text { Casein (\%) } \\
2\end{array}$} & \multirow{3}{*}{$\begin{array}{c}\mathrm{KH}_{2} \mathbf{P O}_{\mathbf{4}}(\boldsymbol{\%}) \\
0.06\end{array}$} & \multirow{3}{*}{$\begin{array}{c}\mathrm{CaCl}_{2}(\%) \\
0.004\end{array}$} & \multirow{3}{*}{$\begin{array}{c}\begin{array}{c}\text { Inoculum } \\
(\%)\end{array} \\
2\end{array}$} & \multicolumn{2}{|c|}{ Enzyme activity (U/ml) } \\
\hline & & & & & & Obs & Predicted \\
\hline & & & & & & 17250 & 17155 \\
\hline 2 & 0.5 & 2 & 0.06 & 0.004 & 1 & 18070 & 17710 \\
\hline 3 & 0.2 & 4 & 0.06 & 0.004 & 1 & 13860 & 12591 \\
\hline 4 & 0.5 & 4 & 0.06 & 0.004 & 2 & 16300 & 16626 \\
\hline 5 & 0.2 & 2 & 0.1 & 0.004 & 1 & 17270 & 16806 \\
\hline 6 & 0.5 & 2 & 0.1 & 0.004 & 2 & 19800 & 20931 \\
\hline 7 & 0.2 & 4 & 0.1 & 0.004 & 2 & 10560 & 10782 \\
\hline 8 & 0.5 & 4 & 0.1 & 0.004 & 1 & 19800 & 19757 \\
\hline 9 & 0.2 & 2 & 0.06 & 0.008 & 1 & 19360 & 18401 \\
\hline 10 & 0.5 & 2 & 0.06 & 0.008 & 2 & 21230 & 21866 \\
\hline 11 & 0.2 & 4 & 0.06 & 0.008 & 2 & 16390 & 16177 \\
\hline 12 & 0.5 & 4 & 0.06 & 0.008 & 1 & 12570 & 12032 \\
\hline 13 & 0.2 & 2 & 0.1 & 0.008 & 2 & 16830 & 17361 \\
\hline 14 & 0.5 & 2 & 0.1 & 0.008 & 1 & 8030 & 8296 \\
\hline 15 & 0.2 & 4 & 0.1 & 0.008 & 1 & 6600 & 5958 \\
\hline 16 & 0.5 & 4 & 0.1 & 0.008 & 2 & 19800 & 20753 \\
\hline 17 & 0.05 & 3 & 0.08 & 0.006 & 1.5 & 10230 & 11632 \\
\hline 18 & 0.65 & 3 & 0.08 & 0.006 & 1.5 & 18590 & 17332 \\
\hline 19 & 0.35 & 1 & 0.08 & 0.006 & 1.5 & 18950 & 18536 \\
\hline 20 & 0.35 & 5 & 0.08 & 0.006 & 1.5 & 12000 & 12559 \\
\hline 21 & 0.35 & 3 & 0.04 & 0.006 & 1.5 & 22220 & 23414 \\
\hline 22 & 0.35 & 3 & 0.12 & 0.006 & 1.5 & 21500 & 20541 \\
\hline 23 & 0.35 & 3 & 0.08 & 0.002 & 1.5 & 20780 & 20984 \\
\hline 24 & 0.35 & 3 & 0.08 & 0.01 & 1.5 & 18150 & 18091 \\
\hline 25 & 0.35 & 3 & 0.08 & 0.006 & 0.5 & 10000 & 11932 \\
\hline 26 & 0.35 & 3 & 0.08 & 0.006 & 2.5 & 21230 & 19442 \\
\hline 27 & 0.35 & 3 & 0.08 & 0.006 & 1.5 & 24200 & 23901 \\
\hline 28 & 0.35 & 3 & 0.08 & 0.006 & 1.5 & 23650 & 23901 \\
\hline 29 & 0.35 & 3 & 0.08 & 0.006 & 1.5 & 24530 & 23901 \\
\hline 30 & 0.35 & 3 & 0.08 & 0.006 & 1.5 & 23540 & 23901 \\
\hline 31 & 0.35 & 3 & 0.08 & 0.006 & 1.5 & 23760 & 23901 \\
\hline 32 & 0.35 & 3 & 0.08 & 0.006 & 1.5 & 23870 & 23901 \\
\hline
\end{tabular}

\subsection{Optimization by response surface methodology}

The next step in the formulation of the medium was to determine the optimum levels of significant variables for serralysin production. For this purpose, the Response Surface Methodology (RSM), using a central composite design (CCD), was adopted for the augmentation of total protease production. The significant variables utilized were as follows: dextrose, casein, potassium phosphate, calcium chloride and inoculum size, each of which was assessed at five coded levels $[-2,-1,0,+1$, and +2$]$, as is shown in Table 4. A total of 32 experiments were conducted. All variables were taken at a central coded value, which was considered as zero. The minimum and maximum ranges of the variables were used, and the full experimental plan with regard to their values in actual and coded form is provided in Table 5. The response values $(\mathrm{Y})$ in each trial were the average of the triplicates.

\subsection{Statistical analysis and modeling}

The data obtained from RSM on serralysin production were subjected analysis of variance (ANOVA). The experimental results of RSM were fitted via the response surface regression procedure, using the following second order polynomial equation:

$$
Y=\beta_{0}+\Sigma \beta_{i} X_{i}+\Sigma \beta_{i i} X_{i}^{2}+\Sigma \beta_{i j} X_{i} X_{j}
$$

Here $Y$ is the response (serralysin production, $\mathrm{U} / \mathrm{ml}$ ), $X_{i}$ and $X_{j}$ are independent variables, $\beta_{0}$ is the intercept; $\beta_{\mathrm{i}}$, and $\beta_{\mathrm{j}}$ are linear coefficients; $\beta_{\mathrm{ii}}$ and $\beta_{\mathrm{jj}}$ are squared coefficients; $\beta_{\mathrm{ij}}$ is interaction coefficients. However, in this study, the independent variables were coded as $X_{1}, X_{2}, X_{4}, X_{6}$ and $X_{7}$. Thus, the second order polynomial equation can be presented as follows:

$Y=\beta_{0}+\beta_{1} X_{1}+\beta_{2} X_{2}+\beta_{4} X_{4}+\beta_{6} X_{6}+\beta_{7} X_{7}+\beta_{11} X_{I} X_{1}+\beta_{12} X_{I} X_{2}+$ $\beta_{14} X_{1} X_{4}+\beta_{16} X_{1} X_{6}+\beta_{17} X_{1} X_{7}+\beta_{22} X_{2} X_{2}+\beta_{24} X_{2} X_{4}+\beta_{26} X_{2} X_{6}+$ $\beta_{27} X_{2} X_{7}+\beta_{44} X_{4} X_{4}+\beta_{46} X_{4} X_{6}+\beta_{47} X_{4} X_{7}+\beta_{66} X_{6} X_{6}+\beta_{67} X_{6} X_{7}+$ $\beta_{77} X_{7} X_{7}$

The statistical software package, Minitab 15 was used for the regression analysis of the experimental data, and also to plot the response surface graphs. The statistical significance of the model equation and the model terms was evaluated via the Fisher's test. The quality of fit of the second-order polynomial model equation was expressed via the coefficient of determination $\left(R^{2}\right)$ 
and the adjusted $\mathrm{R}^{2}$. The fitted polynomial equation was then expressed in the form of three-dimensional surface plots, in order to illustrate the relationship between the responses and the experimental levels of each of the variables utilized in this study. The point optimization method was employed in order to optimize the level of each variable for maximum response. The combination of different optimized variables, which yielded the maximum response, was determined in an attempt to verify the validity of the model.

\section{RESULTS \& DISCUSSION}

\subsection{Screening of significant variables using Plackett-Burman design}

For the rapid evaluation of the effects of the various medium components, Plackett-Burman experimental design proved to be a valuable tool. Since this design is a preliminary optimization technique, which tests only two levels of each factor, it cannot provide the optimal quantity of each factor required for the optimum enzyme production. This technique, however, provides indications of how each factor tends to effect bacterial growth and enzyme production [26]. In the present study a total of seven factors were analyzed with regard to their effects on protease production using a Plackett-Burman design (Table 1). The design matrix selected for the screening of significant factors for serralysin production and the corresponding responses are shown in Table 2. The adequacy of the model was calculated, and the variables evidencing statistically significant effects were screened via Student's t-test for ANOVA (Table 3). Factors evidencing P-values of less than 0.05 were considered to have significant effects on the response, and were therefore selected for further optimization studies. Dextrose and casein, with a probability value of 0.007 , were determined to be the most significant factors, followed by inoculum (0.029), $\mathrm{KH}_{2} \mathrm{PO}_{4}$ (0.041), and $\mathrm{CaCl}_{2}(0.05)$. The lower probability values indicate the more significant factors on the production of serralysin. One of the five significant variables screened, dextrose, exerted a negative effect, whereas the other variables, casein, $\mathrm{KH}_{2} \mathrm{PO}_{4}$ and $\mathrm{CaCl}_{2}$ exerted positive effects on protease production. All other insignificant variables including $\mathrm{NaCl}$ and $\mathrm{MgSO}_{4}$ were neglected, and the optimum levels of the five variables, were further determined by an RSM design. Standardized effect of all the seven factors with respect to serralysin enzyme activity also showed the significant factors importance in pareto chart (Figure 1).

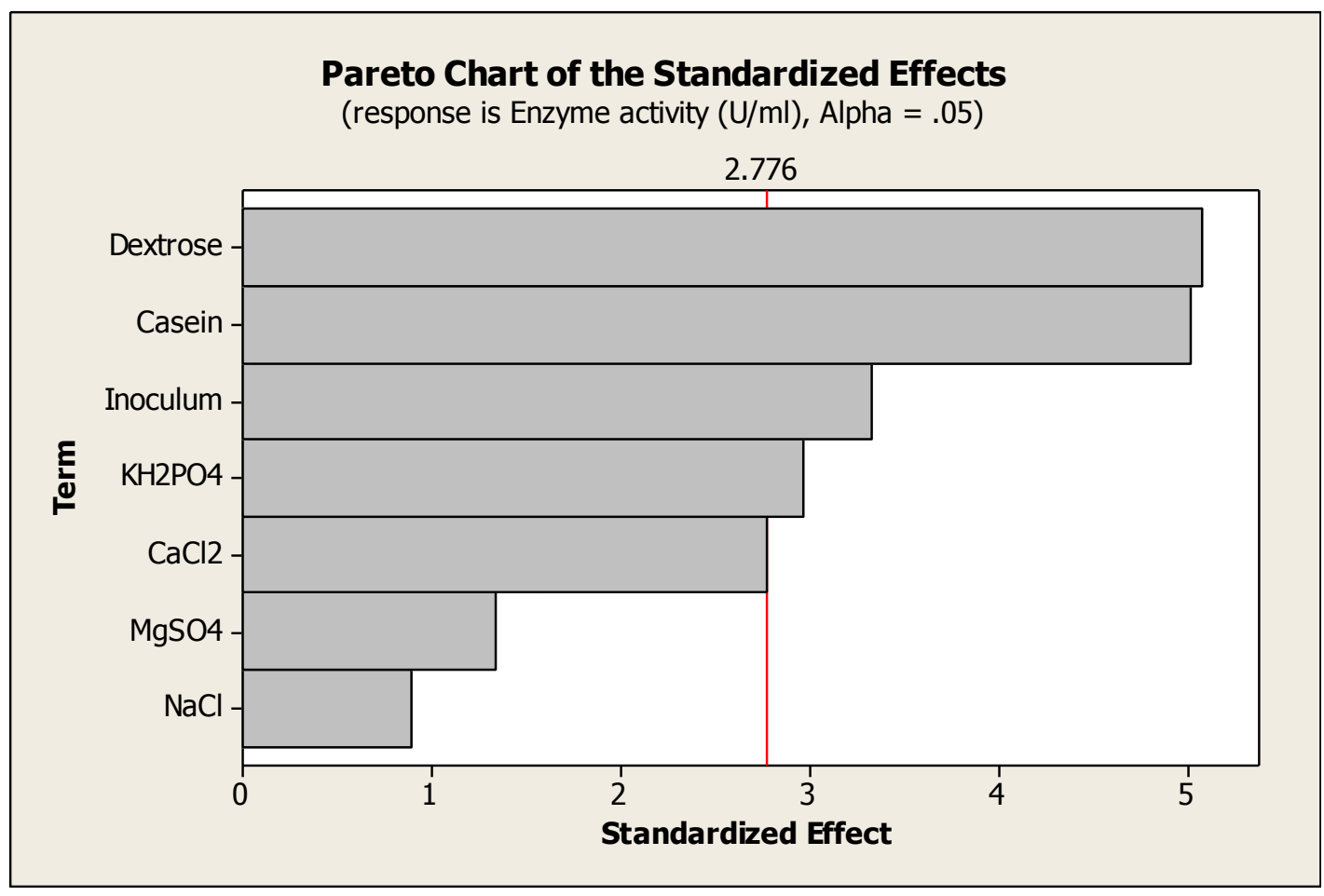

Fig. 1: Pareto chart for Serralysin enzyme activity (U/ml) X1-X7 
Table 6: Model coefficient estimated by multiple linear regressions

\begin{tabular}{|c|c|c|c|c|}
\hline Term & Coefficient & SE Coefficient & T-stat & P - value \\
\hline Constant & 23900.9 & 551.0 & 43.374 & 0.000 \\
\hline Dextrose $\left(X_{I}\right)$ & 2850.0 & 564.0 & 5.053 & 0.000 \\
\hline Casein $\left(X_{2}\right)$ & -2988.3 & 564.0 & -5.298 & 0.000 \\
\hline $\mathrm{KH}_{2} \mathrm{PO}_{4}\left(X_{4}\right)$ & -1418.7 & 564.0 & -2.627 & 0.024 \\
\hline $\mathrm{CaCl}_{2}\left(X_{6}\right)$ & -1446.7 & 564.0 & -2.565 & 0.026 \\
\hline Inoculum $\left(X_{7}\right)$ & 3775.0 & 564.0 & 6.658 & 0.000 \\
\hline$X_{I} * X_{I}$ & -9418.6 & 1020.3 & -9.231 & 0.000 \\
\hline$X_{2} * X_{2}$ & -8353.6 & 1020.3 & -8.187 & 0.000 \\
\hline$X_{4} * X_{4}$ & -1968.6 & 1020.3 & -1.929 & 0.080 \\
\hline$X_{6} * X_{6}$ & -4363.6 & 1020.3 & -4.277 & 0.001 \\
\hline$X_{7} * X_{7}$ & -8213.6 & 1020.3 & -8.050 & 0.000 \\
\hline$X_{1} * X_{2}$ & 6160.0 & 1381.5 & 4.459 & 0.001 \\
\hline$X_{1} * X_{4}$ & 3715.0 & 1381.5 & 2.689 & 0.021 \\
\hline$X_{1} * X_{6}$ & -3145.0 & 1381.5 & -2.276 & 0.044 \\
\hline$X_{1} * X_{7}$ & 3680.0 & 1381.5 & 2.664 & 0.022 \\
\hline$X_{2} * X_{4}$ & 2905.0 & 1381.5 & 2.103 & 0.059 \\
\hline$X_{2} * X_{6}$ & 445.0 & 1381.5 & 0.322 & 0.753 \\
\hline$X_{2} * X_{7}$ & -540.0 & 1381.5 & -0.391 & 0.703 \\
\hline$X_{4} * X_{6}$ & -5060.0 & 1381.5 & -3.663 & 0.004 \\
\hline$X_{4} * X_{7}$ & 1995.0 & 1381.5 & 1.444 & 0.177 \\
\hline$X_{6} * X_{7}$ & 8195.0 & 1381.5 & 5.932 & 0.000 \\
\hline
\end{tabular}

$\mathrm{S}=1381.53 \quad$ PRESS $=545157207$

$\mathrm{R}-\mathrm{Sq}=97.31 \%, \mathrm{R}-\mathrm{Sq}(\operatorname{adj})=92.43 \%$

Table 7: Analysis of variance (ANOVA) for quadratic model

\begin{tabular}{|c|c|c|c|c|c|c|}
\hline Source & Degree of freedom & Seq SS & Adjusted SS & Adjusted MS & $\mathbf{F}$ & $\mathbf{p}$ \\
\hline Regression & 20 & 760686741 & 760686741 & 38034337 & 19.93 & 0.000 \\
\hline Linear & 5 & 212645050 & 212645050 & 42529010 & 22.28 & 0.000 \\
\hline Square & 5 & 367191141 & 367191141 & 73438228 & 38.48 & 0.000 \\
\hline Interaction & 10 & 180850550 & 180850550 & 18085055 & 9.48 & 0.000 \\
\hline Residual Error & 11 & 20994809 & 20994809 & 1908619 & & \\
\hline Lack of fit & 6 & 20299059 & 20299059 & 3383177 & 24.31 & 0.002 \\
\hline Pure Error & 5 & 695750 & 695750 & 139150 & & \\
\hline Total & 31 & 781681550 & & & & \\
\hline
\end{tabular}

\subsection{Optimization of significant variables using response surface methodology}

The experiments conducted in the present study were targeted toward the construction of a quadratic model consisting of 32 trials. The design matrix and the corresponding results of RSM experiments to determine the effects of five independent variables are shown in Table 5, along with the mean predicted values. The ANOVA analysis of the optimization study (Table 7) indicated that the most of the model terms, were significant $(\mathrm{P}<0.05)$, except few insignificant terms like, $X_{4} * X_{4}, X_{2} * X_{7}, X_{2} * X_{6}, X_{2} * X_{4}$ and $X_{4} * X_{7}$. The linear effects of dextrose, casein and inoculum ( $\mathrm{P}$ $<0.001)$ were determined to be more significant than the effects of the other two variables. These results indicate that the concentration of the carbon and nitrogen source with respect to a particular amount of inoculum size bears a direct relationship to serralysin production. The high F-value and non-significant lack of fit indicate that the model is a good fit. The P-values for the model $(<0.0001)$ and lack of fit $(0.002)$ also suggested that the obtained experimental data was a good fit with the model (Table 6). The regression equation coefficients were calculated and the data was fitted to a second-order polynomial equation. The response, serralysin production (Y) by Serratia marcescens RSPB11 can be expressed in terms of the following regression equation:
$Y=23900.9+2850.0 X_{1}-2988.3 X_{2}-1418.7 X_{4}-1446.7 X_{6}+$ $3775.0 X_{7}-9418.6 X_{1} X_{1}+6160.0 X_{1} X_{2}+3715.0 X_{1} X_{4}-3145.0 X_{1} X_{6}$ $+3680.0 X_{1} X_{7}-8353.6 X_{2} X_{2}-5060.0 X_{4} X_{6}-4363.6 X_{6} X_{6}+8195.0$ $X_{6} X_{7}-8213.6 X_{7} X_{7}$

Where $Y$ (serralysin production in $\mathrm{U} / \mathrm{ml}$ ) is the response and the coded values of the test variables $X_{1}$ is dextrose, $X_{2}$ is casein, $X_{4}$ is potassium phosphate, $X_{6}$ is calcium chloride and $X_{7}$ is inoculum size. The regression equation obtained from the ANOVA showed that the $\mathrm{R}^{2}$ [multiple correlation coefficient] was 0.9731. Since this value is $>0.75$, thus it indicates fitness of the model. This is an estimate of the fraction of overall variation in the data accounted by the model, and thus the model is capable of explaining $97.31 \%$ of the variation in response where as the 'adjusted $\mathrm{R}^{2}$ ' is $92.43 \%$. This indicates that the model is good (For a good statistical model, the $\mathrm{R}^{2}$ value should be in the range of 0 1.0 ), where the closer $\mathrm{R}^{2}$ is to 1.0 , the stronger the model and the better it predicts the response [11].

In order to determine the optimal levels of each variable for maximum protease production, three-dimensional response surface plots were constructed by plotting the response (protease production) on the Z-axis against any two independent variables, while maintaining other variables at their optimal levels. Figure $2 \mathrm{a}-\mathrm{d}$ indicates the interaction of dextrose with other variables viz., 
casein, $\mathrm{KH}_{2} \mathrm{PO}_{4}, \mathrm{CaCl}_{2}$ and inoculum and their effects on serralysin production. The Figure depicts the importance of glucose on maximizing protease production (> 20,000 $\mathrm{U} / \mathrm{ml}$ ) where the concentration of glucose should be in the range of 0.2 $0.5 \%(\mathrm{w} / \mathrm{v})$. Figure 2(a) clarifies that serralysin production is dependent on interaction of dextrose and casein and is also evidenced by their p-value of 0.001 (Table 6) which is highly significant. Similar effect between carbon and nitrogen source has been observed in case of protease production by Serratia rubidea [15]. Interaction of casein with other variables like $\mathrm{KH}_{2} \mathrm{PO}_{4}, \mathrm{CaCl}_{2}$ and inoculum can be observed in Figure 2(e, f, g), where > 24,000 $\mathrm{U} / \mathrm{ml}$ serralysin can be yielded if the casein concentration is around $3 \%(\mathrm{w} / \mathrm{v})$ in the production media. Serralysin production in this microbial strain is inducible with the presence of casein hence it is an important and significant variable in serralysin production at individual level (p-value of 0.000) however, the presence of this nitrogen source doesn't signifies the interaction with other variables like (Table 6). The flat surface between $\mathrm{KH}_{2} \mathrm{PO}_{4}$ and dextrose in Figure 2 (b), $\mathrm{KH}_{2} \mathrm{PO}_{4}$ and casein in Figure 2 (e),
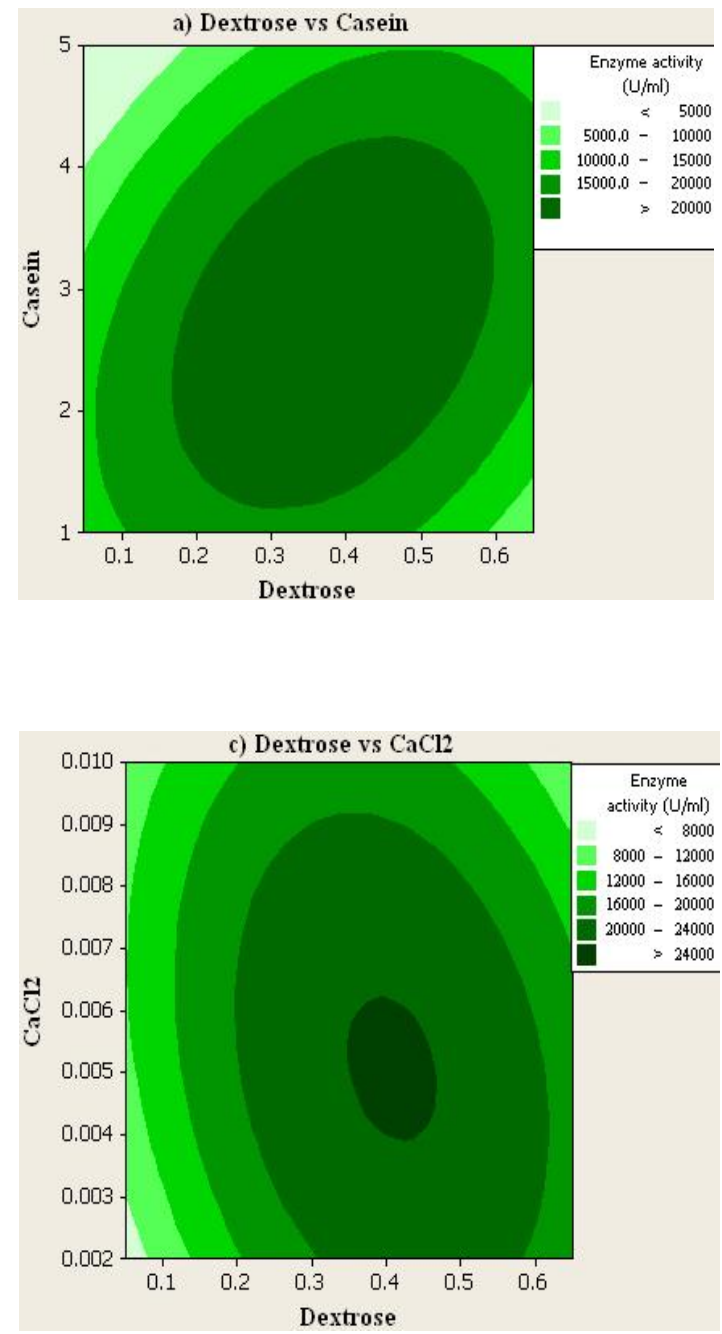

$\mathrm{KH}_{2} \mathrm{PO}_{4}$ and inoculum in Figure 2 (i) indicates that $\mathrm{KH}_{2} \mathrm{PO}_{4}$ doesn't interact with any other media components except $\mathrm{CaCl}_{2}$ where a significant p-value of 0.004 (Table 6) were observed between these two variables. The influence of physical and nutritional parameter variations on serralysin production using the microbe Serratia marcescens RSPB11 was depicted in Table 8. It is evident from the table that a step by step improvement of serralysin production is clearly visible, where the initial yeast extract-peptone-glucose medium composition has given 5,363 $\mathrm{U} / \mathrm{ml}$ followed by the replacement of casein as nitrogen source and change in dextrose concentration yielded 15,290 U/ml. At this step a 2.85 fold rise in serralysin production exhibits the possible use of the isolated microbe Serratia marcescens RSPB11 for achieving higher yields of extracellular protease. Overall variation in nutritional parameters has resulted in 4.46 fold rise of serralysin yield, compared to yeast extract-peptone-glucose medium and a 1.56 fold rise in serralysin yield compared to unoptimized casein medium. This could be observed with the use of Plackett-Burman and response surface methodology, respectively.
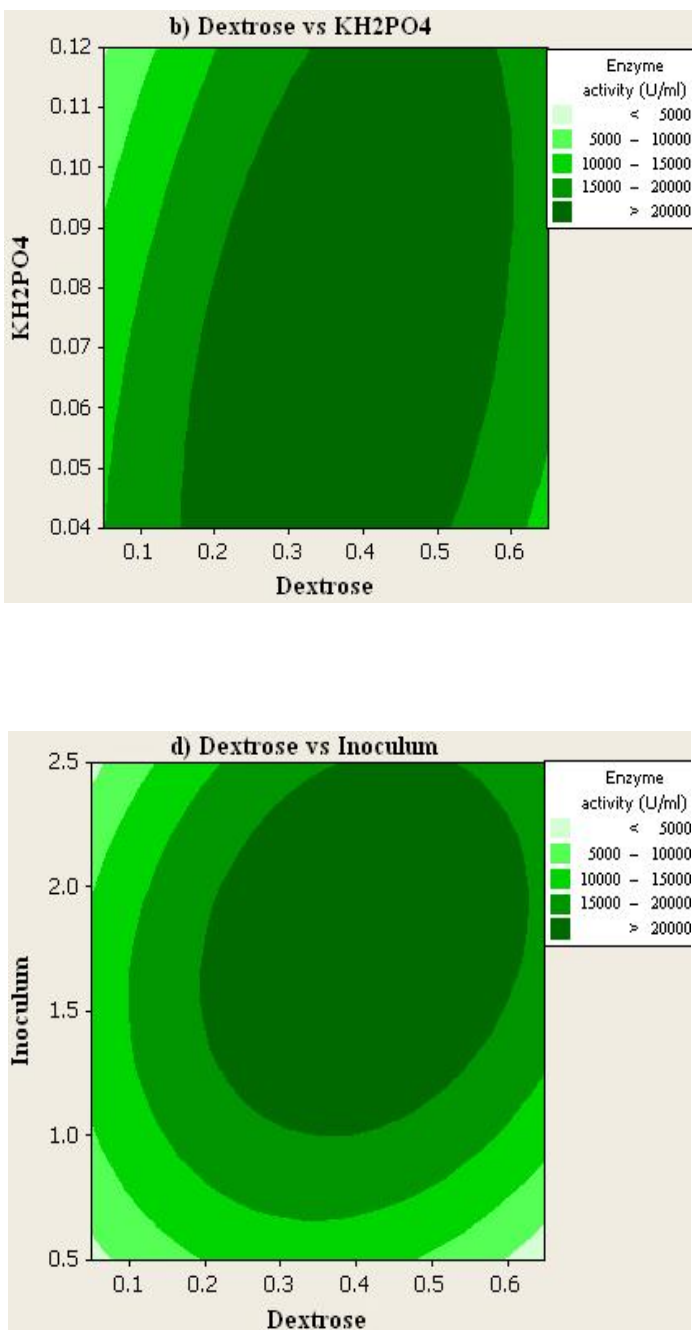

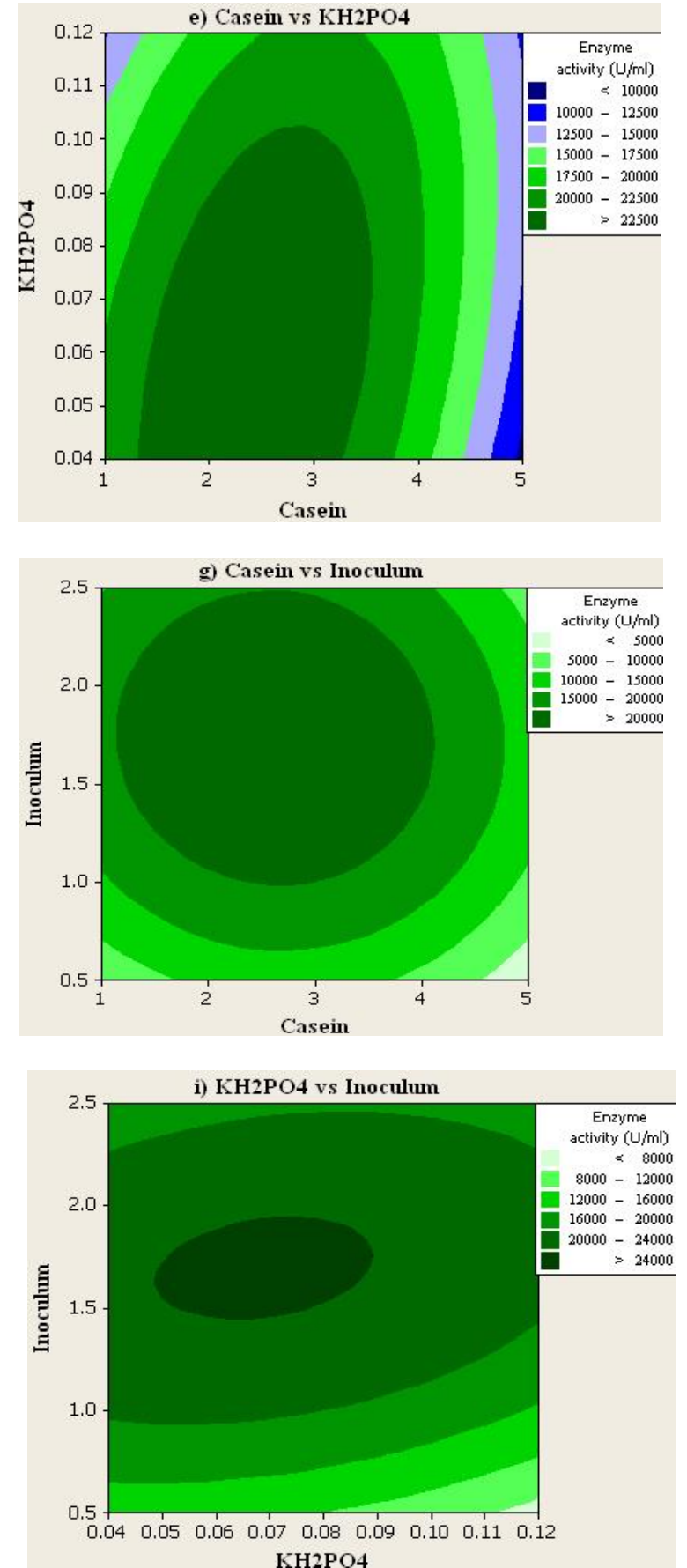
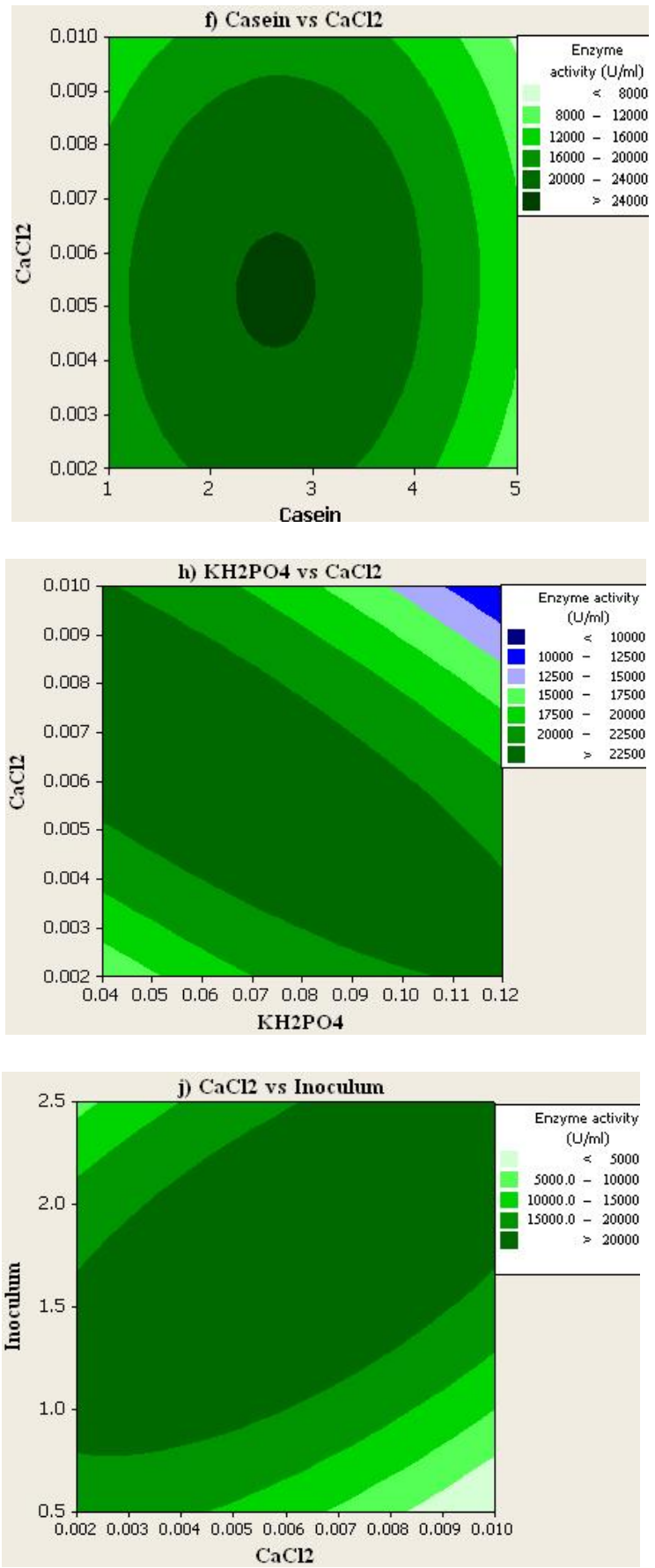

Fig. 2: Response surface plots : interactive effects of (A) dextrose and casein, (B) dextrose and $\mathrm{KH}_{2} \mathrm{PO}_{4},(\mathrm{C})$ dextrose and $\mathrm{CaCl}$, (D) dextrose and inoculum, (E) casein and $\mathrm{KH}_{2} \mathrm{PO}_{4},(\mathrm{~F})$ casein and $\mathrm{CaCl}_{2}$, $(\mathrm{G})$ casein and inoculum, (H) $\mathrm{KH}_{2} \mathrm{PO}_{4}$ and $\mathrm{CaCl}_{2}$, (I) $\mathrm{KH}_{2} \mathrm{PO}_{4}$ and inoculum, (J) CaCl 2 and inoculum on serralysin production.

\subsection{Validation of the model}

The validation of the statistical model and regression equation were conducted by taking $0.35 \%$ dextrose, $3 \%$ casein, $0.08 \% \mathrm{KH}_{2} \mathrm{PO}_{4}, 0.005 \% \mathrm{CaCl}_{2}(\mathrm{w} / \mathrm{v})$ and $1.5 \%(\mathrm{v} / \mathrm{v})$ inoculum size. Under these optimized conditions, the predicted response for protease production was $24001.5 \mathrm{U} / \mathrm{ml}$, with composite desirability $=0.9993$ and the observed experimental value was $23910 \mathrm{U} / \mathrm{ml}$, which is an average of three replicates. These results confirmed the validity of the model, and the experimental values were determined to be quite close to the predicted values. 
Table 8: An overview of serralysin production improvement under different conditions using the batch culture of Serratia marcescens RSPB11.

\begin{tabular}{|c|c|c|c|c|}
\hline Method of optimization & Physical parameters & $\begin{array}{c}\text { Nutritional parameters \% } \\
(\mathbf{w} / \mathbf{v})\end{array}$ & $\begin{array}{c}\text { Enzyme activity } \\
(\mathrm{U} / \mathrm{ml})\end{array}$ & Ref \\
\hline One factor at a time & $\begin{array}{l}30^{\circ} \mathrm{C}, 150 \mathrm{rpm}, 1 \% \text { Inoculum (OD600nm 1.5), } \\
\mathrm{pH} 7.0\end{array}$ & $\begin{array}{l}\text { Yeast extract-1.0, Peptone-1.0, } \\
\text { Dextrose- } 0.2, \quad \mathrm{MgSO}_{4}-0.02 \text {, } \\
\mathrm{KH}_{2} \mathrm{PO}_{4}-0.02, \mathrm{NaCl}-0.02\end{array}$ & 5,363 & 24 \\
\hline One factor at a time & -do- & $\begin{array}{l}\text { Tryptone-2.0, Dextrose - } \\
1.0, \mathrm{MgSO}_{4}-0.02, \mathrm{KH}_{2} \mathrm{PO}_{4^{-}} \\
0.02, \mathrm{NaCl}-0.02\end{array}$ & 9,845 & 8 \\
\hline Unoptimized conditions & -do- & $\begin{array}{l}\text { Casein-2.0, } \\
\mathrm{MgSO}_{4}-0.02, \quad \mathrm{KH}_{2} \mathrm{PO}_{4}-0.02, \\
\mathrm{NaCl}-0.02, \mathrm{CaCl}_{2}-0.002\end{array}$ & 15,290 & $\begin{array}{l}\text { Current } \\
\text { study }\end{array}$ \\
\hline Plackett-Burman design & $30^{\circ} \mathrm{C}, 150 \mathrm{rpm}, 1.5 \%(\mathrm{v} / \mathrm{v})$ Inoculum (OD600nm 1.5$), \mathrm{pH} 7.0$ & $\begin{array}{l}\text { Casein-2.0, } \\
\mathrm{MgSO}_{4}-0.1, \quad \mathrm{KH}_{2} \mathrm{PO}_{4}-0.08, \\
\mathrm{NaCl}^{-0.1}, \mathrm{CaCl}_{2}-0.003\end{array}$ & 17,900 & -do- \\
\hline $\begin{array}{l}\text { Response Surface } \\
\text { Methodology }\end{array}$ & -do- & $\begin{array}{l}\text { Casein-3.0, Dextrose- } \\
0.35, \quad \mathrm{MgSO}_{4}-0.1, \quad \mathrm{KH}_{2} \mathrm{PO}_{4-} \\
0.08, \mathrm{NaCl}-0.1, \mathrm{CaCl}_{2}-0.005\end{array}$ & 23,910 & -do- \\
\hline
\end{tabular}

Table 9: Serralysin production from different sources at various cultivation conditions.

\begin{tabular}{|c|c|c|c|c|c|}
\hline Organism & $\begin{array}{c}\text { Method of } \\
\text { optimization }\end{array}$ & Physical parameters & $\begin{array}{c}\text { Nutritional parameters \% } \\
(\mathbf{w} / \mathbf{v})\end{array}$ & $\begin{array}{l}\text { Enzyme activity } \\
(\mathrm{U} / \mathrm{ml})\end{array}$ & Ref \\
\hline $\begin{array}{l}\text { Serratia marcescens } \\
\text { RSPB11 }\end{array}$ & $\begin{array}{l}\text { Plackett-Burman \& } \\
\text { RSM design }\end{array}$ & $\begin{array}{l}30^{\circ} \mathrm{C}, 150 \mathrm{rpm}, 1.5 \%(\mathrm{v} / \mathrm{v}) \text { Inoculum, } \mathrm{pH} \\
7.0\end{array}$ & $\begin{array}{l}\text { Casein-3.0, Dextrose- } \\
0.35, \quad \mathrm{MgSO}_{4}-0.1, \quad \mathrm{KH}_{2} \mathrm{PO}_{4-} \\
0.08, \mathrm{NaCl}-0.1, \mathrm{CaCl}_{2}-0.005\end{array}$ & 23,910 at $48 \mathrm{~h}$ & $\begin{array}{l}\text { Current } \\
\text { study }\end{array}$ \\
\hline $\begin{array}{l}\text { Serratia marcescens ATCC } \\
25419\end{array}$ & 51 bioreactor & $\begin{array}{l}30^{\circ} \mathrm{C}, 30 \% \text { of dissolved oxygen saturation, } \\
\mathrm{pH} 7.6\end{array}$ & 2.61 Fresh sweet whey & 8,800 at $36 \mathrm{~h}$ & 28 \\
\hline Serratia marcescens SB08 & $\begin{array}{l}\text { Plackett-Burman \& } \\
\text { RSM design }\end{array}$ & $30^{\circ} \mathrm{C}, 100 \mathrm{rpm}, 1 \%$ inoculum, $\mathrm{pH} 6.0$ & $\begin{array}{l}\text { Peptone- } 0.5 \text {, Beef extract- } 0.3 \text {, } \\
\text { Yeast extract- } 0.3, \mathrm{NaCl}-0.5\end{array}$ & 281.23 at $51 \mathrm{~h}$ & 29 \\
\hline $\begin{array}{l}\text { Serratia marcescens } \\
\text { NRRL B-23112 }\end{array}$ & EVOP design & $25^{\circ} \mathrm{C}, 180 \mathrm{rpm}, 1 \%$ inoculum, $\mathrm{pH} 6.0$ & $\begin{array}{l}\text { Maltose- } 4.5, \text { Soybean meal- } \\
6.5, \mathrm{~K}_{2} \mathrm{HPO}_{4}-0.8, \mathrm{NaCl}-0.5\end{array}$ & 7,333 at $48 \mathrm{~h}$ & 30 \\
\hline $\begin{array}{l}\text { Serratia marcescens } \\
\text { NRRL B-23112 }\end{array}$ & 51 bioreactor & $25^{\circ} \mathrm{C}, 400 \mathrm{rpm}, 0.075 \mathrm{vvm}, \mathrm{pH} 7.0$ & $\begin{array}{l}\text { Maltose- } 4.5 \text {, Soybean meal- } \\
6.5, \mathrm{~K}_{2} \mathrm{HPO}_{4}-0.8, \mathrm{NaCl}-0.5\end{array}$ & 11,580 at $42 \mathrm{~h}$ & 23 \\
\hline
\end{tabular}

\section{CONCLUSION}

For the economization of the production process, enzyme over production is essential, and can be achieved both by genetic manipulation and media engineering. Using recombinants to increase the production of enzymes may not be able for certain metabolites.

Thus, media manipulation is the better alternative for the overproduction of enzymes, as the secretion of metabolism products is an important component of the survival strategies of some microbes occupying certain environments [27]. Every microorganism evidences its own idiosyncratic physicochemical and nutritional requirements for growth and protease secretion and their production yields differ considerably in microbial strains and mainly influenced by nutritional status of the growth medium or environmental nitch. Serratia marcescens RSPB11 with higher serralysin production potential to that of various strains has been compared in Table 9. The protease activity under unoptimized conditions was $15290 \mathrm{U} / \mathrm{ml}$, which signifies that $>50 \%$ rise in serralysin production has been achieved with the current statistical optimization.

\section{ACKNOWLEDGEMENT}

One of the authors, P. Lakshmi Bhargavi is greatly indebted to Council of Scientific and Industrial Research, New
Delhi for financial support in the form of Senior Research Fellowship.

\section{REFERENCES}

1. Molla A. Activation of hageman factor and prekallikrein and generation of kinin by various microbial proteinases. The journal of Biological Chemistry. 1989; 264:10589-10594.

2. Klein G, Kullich W. Short-term treatment of painful osteoarthritis of the knee with oral enzymes, a randomized, double-blind study versus diclofenac. Clinical Drug Investigation. 2000; 19:15-23.

3. Matsumoto K, Maeda H, Takata K, Kamata R, Okamura R Purification and characterization of four proteases from a clinical isolate of Serratia marcescens kums 3958. Journal of Bacteriology .1984; 157:225-232.

4. Maeda H. Role of microbial proteases in pathogenesis. Microbiology and Immunology.1996; 40: 685-699.

5. Kumeta H, Hoshino T, Goda T, Okayama T, Shimada T, Ohgiya S, Matsuyama $\mathrm{H}$, Ishizaki $\mathrm{K}$. Identification of a member of the serralysin family isolated from a psychrotrophic bacterium Pseudomonas fluorescens 114. Bioscience Biotechnology and Biochemistry. 1999; 63:1165-1170.

6. Ulhas P, Ambalal C. Purification and characterization of solventtolerant, thermostable, alkaline metalloprotease from alkalophilic Pseudomonas aeruginosa MTCC 7926. Journal of Chemical Technology and Biotechnology. 2009; 84:1255-1262.

7. Romero F, Garcia LA, Salas J, Diaz M, Quiros L. Production, purification and partial characterization of two extracellular proteases from Serratia marcescens grown in whey. Process Biochemistry. 2001; 36: 501-515. 
8. Bhargavi PL, Kumar BS, Prakasham RS. Impact of nutritional factors verses biomass and serralysin production in isolated Serratia marcescens. Current Trends in Biotechnology and Pharmacy. 2012; 6: 441-448

9. Bhargavi PL, Prakasham RS. A fibrinolytic, alkaline and thermostable metalloprotease from the newly isolated Serratia sp RSPB11. International Journal of Biological Macromolecules. 2013; 66: 479-486.

10. Adinarayana K, Ellaiah $\mathrm{P}$. Response surface optimisation of the critical medium components for the production of alkaline protease by a newly isolated Bacillus sp. Journal of Pharmacy and Pharmaceutical Science. 2002; 5:272-278.

11. Khuri AI, Cornell JA. Response surfaces: design and analysis. Marcel Dekker: New York. 1987.

12. Ledesma, J, Bortolato AS, Boschetti CE, Martino DM. Optimization of environmentally benign polymers based on thymine and polyvinyl sulfonate using plackett-burman design and surface response. Journal of Chemistry. 2013; Article ID 947137:1-9.

13. Saxena R, Singh R. Statistical optimization of conditions for protease production from Bacillus sp. Acta Biol Szegediensis. 2010; 54: 135141

14. Hymavathi M, Sathish T, Rao CS, Prakasham RS. Enhancement of L-asparaginase production by isolated Bacillus circulans (MTCC 8574) using response surface methodology. Applied Biochemistry and Biotechnology. 2009; 159:191-198.

15. Doddapaneni K, Tatineni KR, Potumarthi R, Mangamoori LN. Optimization of media constituents through response surface methodology for improved production of alkaline proteases by Serratia rubidaea. Journal of Chemical Technology and Biotechnology. 2007; 82:721-729.

16. Mishra A, Kumar S, Kumar S. Application of Box-Benhken experimental design for optimization of laccase production by Coriolus versicolor MTCC138 in solid-state fermentation. Journal of Scientific and Industrial Research. 2008; 67:1098-1107.

17. Mukherjee AK, Rai SK. A statistical approach for the enhanced production of alkaline protease showing fibrinolytic activity from a newly isolated Gram-negative Bacillus sp. strain AS-S20-I. New Biotechnology. 2011; 28:182-189

18. Chennupati S, Potumarthi R, Rao MG, Manga PL, Sridevi M, Jetty A. Multiple responses optimization and modeling of lipase production by Rhodotorula mucilaginosa MTCC-8737 using response surface methodology. Applied Biochemistry and Biotechnology. 2009; 159:317-329.
19. Rodriguez-Duran, Luis V, Contreras-Esquivel JC, Rodriguez R, Prado-Barragan LA, Aguilar CN. Optimization of tannase production by Aspergillus niger in solid-state packed-bed bioreactor. Journal of Microbiology Biotechnology. 2011;21:960-967.

20. Srinivasulu Y, Subramanyam M. Expression and optimization of capsular polysaccharide production by Neisseria meningitidis serogroup- A using statistical designs and surface plots. International Journal of Pharmacy and Pharmaceutical Science. 2011; 3:148-151.

21. Cao W, Gong G, Liu X, Hu W, Li Z, Liu H, Li Y. Optimization of epothilone B production by Sorangium cellulosum using multiple steps of the response surface methodology. African Journal of Biotechnology. 2011; 10:11058-11070.

22. Rao, C. S, Sathish T, Mahalaxmi M, Laxmi G. S, Rao RS, Prakasham RS. Modeling and optimization of fermentation factors for enhancement of alkaline protease production by isolated Bacillus circulans using feed-forward neural network and genetic algorithm. Journal of Applied Microbiology. 2008; 104:889-898.

23. Pansuriya RC, Rekha SS. Effects of dissolved oxygen and agitation on production of serratiopeptidase by Serratia marcescens NRRL b23112 in stirred tank bioreactor and its kinetic modeling. Journal of Microbiology and Biotechnology. 2011; 21:430-437.

24. Bhargavi PL, Prakasham RS. Proteolytic enzyme production by isolated Serratia sp RSPB11: role of environmental parameters. Current Trends in Biotechnology and Pharmacy. 2012; 6:55-65.

25. Anson ML. Estimation of pepsin, papain and cathepsin with haemogloblin. Journal of General Physiology.1938; 22:79-89.

26. Plackett RL, Burman JP. The design of optimum multifactorial experiments. Biometrika. 1946; 33:305-325.

27. Dey G, Mitra A, Banerjee R, Maiti BR. Enhanced production of amylase by optimization of nutritional constituents using response surface methodology. Biochemical Engineering Journal. 2001; 7:227-231

28. Ustariz FJ, Laca A, Garcia LA, Diaz M. Fermentation conditions increasing protease production by Serratia marcescens in fresh whey. Revista Tecnica de la Facultad de Ingenieria Universidad del Zulia. 2008; 1:79-89

29. Venil CK, Perumalsamy PL. Application of response surface methodology in medium optimization for protease production by the new strain of Serratia marcescens SB08. Polish Journal of Microbiology. 2009; 58:117-124.

30. Pansuriya RC, Rekha SS. Evolutionary operation (EVOP) to optimize whey-independent serratiopeptidase production from Serratia marcescens NRRL B-23112. Journal of Microbiology and Biotechnology. 2010; 20:950-957.

\section{How to cite this article:}

Bhargavi PL, Prakasham RS. Enhanced fibrinolytic protease production by Serratia marcescens RSPB11 through Plackett-Burman and response surface methodological approaches. J App Biol Biotech. 2016; 4 (03): 006-014. DOI: 10.7324/JABB.2016.40302 